Method A pooled analysis of 10 case-control studies was conducted within the Interlymph Consortium. Overall, the study population included 10786 NHL cases and 12069 controls. Each occupation of study subjects was coded using the 1968 ISCO classification. Risk of NHL, diffuse large B cell lymphoma (DLBCL), follicular Lymphoma (FL), chronic lymphocytic leukaemia (CLL) and T-cell Lymphoma, associated with having been working for one year or more in specific health occupations was calculated as the Odds Ratio (OR) and its 95\% confidence interval $(95 \% \mathrm{CI})$ with unconditional logistic regression, adjusting by age, gender and study area. Risk was also calculated for duration of employment $>10$ years.

Results Health workers employed 10 year or more showed a significant $19 \%$ excess risk of FL, which was restricted to male workers $(\mathrm{OR}=1.62 ; 95 \% \mathrm{CI} 1.02,2.59)$. FL risk was highest $(\mathrm{OR}=2.23,95 \%$ CI 1.17-4.26) among the medical staff, and it was consistent in both genders. Male personal care workers also showed an increase in NHL risk (OR $=2.52$; 95\% CI 1.18 5.36). Risk was not increased among nurses. No consistent patterns of increasing risk was observed for the other NHL subtypes.

Conclusions Shift work, ethylene oxide, and viral agents are well known NHL risk factors among health workers. Our results suggest that risk might be more elevated among the medical staff and among men.

\section{EFFECTIVENESS OF A MULTIDISCIPLINARY INTERVENTION AMONG DUTCH CONSTRUCTION WORKERS ON RESPIRABLE QUARTZ EXPOSURE: RESULTS FROM THE 'RELIEVED WORKING STUDY'}

\footnotetext{
1,2Erik van Deurssen, ${ }^{2}$ Karen Oude Hengel, ${ }^{2}$ Suzanne Spaan, ${ }^{2}$ Henk Goede, ${ }^{2}$ Tim Meijster, ${ }^{2}$ Erik Tielemans, ${ }^{1}$ Dick Heederik, ${ }^{2}$ Anjoeka Pronk. ${ }^{1}$ Institute for Risk Assessment Sciences, Utrecht University, Utrecht, The Netherlands; ${ }^{2}$ TNO, Zeist, The Netherlands
}

\subsection{6/oemed-2014-102362.359}

Objectives A multidisciplinary intervention study aimed at reducing quartz exposure in the Dutch construction industry was performed. We aimed to assess the effect of the intervention on exposure level and psycho-social and organisational factors.

Method Eight participating construction companies were randomly allocated to an intervention $(\mathrm{n}=4)$ or control group ( $\mathrm{n}$ $=4$ ). Following the Intervention Mapping approach, the intervention aimed at engineering, organisational and psycho-social factors. Pre and post-intervention respirable quartz measurements $(n=300)$ were taken from workers from all eight companies. Questionnaires and observation forms were used to assess pre and post psycho-social and organisational factors.

Results Pre-intervention assessment demonstrated highest respirable quartz levels for concrete drillers, tuck pointers and demolishers (GM respectively $0.20,0.18$ and $0.12 \mathrm{mg} / \mathrm{m}^{3}$ ), exceeding the Dutch occupational exposure limit (OEL) in $62 \%$ of the measurements. Identified control measures resulted in 30\% reduction in quartz exposure. More social influence was associated with a 1.5 fold increased use of control measures. The post intervention assessments will become available early 2014 .

Conclusions High exposure levels exceeding the Dutch OEL were observed. Associations between organisational, psychosocial and use of control measures found during the pre-intervention, were taken into consideration when developing the intervention strategy. A comparison between pre and post intervention outcomes will be presented during the conference. The effect of changes in exposure levels as a result of the intervention will be assessed with a health impact assessment model incorporating population dynamics.

\section{AN EXPOSURE ASSESSMENT MODEL FOR LONG WORKING HOURS}

${ }^{1}$ Sadie Conway, ${ }^{1}$ Lisa Pompeii, ${ }^{2}$ David Gimeno. ${ }^{1}$ The University of Texas School of Public Health, Houston, Texas, USA; ${ }^{2}$ The University of Texas School of Public Health, San Antonio, Texas, USA

\subsection{6/oemed-2014-102362.360}

Objectives To operationalize a definition of long working hours that overcomes limitations of existing heterogeneous definitions and to examine the temporal trends of long working hours across worker characteristics in the US.

Method We examined 25 years (1985-2010) of repeated working hour measures from a representative sample of workers in the US Panel Study of Income Dynamics. Self-reported working hours included total annual hours worked, total annual overtime worked, jobs worked, and weekly hours worked by job. An exposure assessment model was produced through the creation of a directed acyclic graph, and a corresponding multivariate model was constructed for purposes of examining long working hours as an independent risk factor for various health outcomes, including cardiovascular disease.

Results An improved measure of working hours was produced in the form of a model that included dimensions of working hour intensity and duration. Descriptive analyses evaluating the frequency and temporal trends of long working hours across demographic and occupational strata were calculated on 31136 participants employed during this study period, with $66.8 \%$ and $32.0 \%$ who worked more than 40 and $50 \mathrm{~h}$ per week on average, respectively, for any year.

Conclusions The longitudinal nature of this study in a large representative sample of US workers using repeated measures of working hours allowed us to operationalize a more comprehensive definition of long working hours, addressing methodological issues identified in previous research and providing enhanced generalizability. We examined the relationship of long working hours with health outcomes while considering participants demographic and occupational characteristics.

\section{INFLUENCE OF FLUORIDE AND HARD MANUAL LABOUR FOR PREVALENCE OF SHOULDER PAIN SYNDROME IN ALUMINIUM POTROOMS}

${ }^{1}$ Vasiliy Shirokov, ${ }^{1}$ Vladimir Gurvich, ${ }^{2}$ Anatoliy Varaksin, ${ }^{1}$ Tatyana Derstuganova. ${ }^{1}$ Federal State Scientific Institution "Ekaterinburg Medical Research Center for Prophylaxis and Health Protection of Industrial Workers", Ekaterinburg, Russia; 'Institute of Industrial Ecology, The Ural Branch of the Russian Academy of Sciences.

\subsection{6/oemed-2014-102362.361}

Objectives To evaluate relative contribution of hard manual labour, fluorides' influence, co-morbid pathology on the prevalence and incidence of shoulder pain syndrome (SPS).

Method One-stage cross-sectional observation of prevalence SPS was investigated. The observed 6094 workers were divided into four groups. The first group was formed by 407 workers of an aluminium plant (elektroliz aluminium), whose professional activity (hard manual labour) is connected the quite big shoulder region loading and fluorides' influence. The 2-nd group consisted of 369 workers with fluorides' influence without manual 